\title{
Role of bile acids and bile acid binding agents in patients with collagenous colitis
}

\author{
K-A Ung, R Gillberg, A Kilander, H Abrahamsson
}

\begin{abstract}
Background-In a retrospective study bile acid malabsorption was observed in patients with collagenous colitis.

Aims-To study the occurrence of bile acid malabsorption and the effect of bile acid binders prospectively in patients with chronic diarrhoea and collagenous colitis. Methods-Over 36 months all patients referred because of chronic diarrhoea completed a diagnostic programme, including gastroscopy with duodenal biopsy, colonoscopy with biopsies, and the ${ }^{75} \mathrm{Se}-$ homocholic acid taurine $\left({ }^{75} \mathrm{SeHCAT}\right)$ test for bile acid malabsorption. Treatment with a bile acid binder (cholestyramine in 24 , colestipol in three) was given, irrespective of the results of the ${ }^{75}$ SeHCAT test.

Results-Collagenous colitis was found in 28 patients (six men, 22 women), 27 of whom had persistent symptoms and completed the programme. Four patients had had a previous cholecystectomy or a distal gastric resection. The ${ }^{75}$ SeHCAT test was abnormal in $12 / 27$ (44\%) of the collagenous colitis patients with ${ }^{75} \mathrm{SeHCAT}$ values $0.5-9.7 \%$, and normal in 15 patients $(56 \%)$. Bile acid binding treatment was followed by a rapid, marked, or complete improvement in $21 / 27(78 \%)$ of the collagenous colitis patients. Rapid improvement occurred in $11 / 12(92 \%)$ of the patients with bile acid malabsorption compared with $10 / 15(67 \%)$ of the patients with normal ${ }^{75}$ SeHCAT tests.

Conclusion-Bile acid malabsorption is common in patients with collagenous colitis and is probably an important pathophysiological factor. Because of a high response rate without serious side effects, bile acid binding treatment should be considered for collagenous colitis, particularly patients with bile acid malabsorption.

(Gut 2000;46:170-175)
\end{abstract}

Division of

Gastroenterology, Department of

Internal Medicine,

Sahlgrenska University

Hospital, S-413 45

Göteborg, Sweden

K-A Ung

R Gillberg

A Kilander

H Abrahamsson

Correspondence to:

Dr K-A Ung.

Accepted for publication

9 September 1999 esis of collagenous colitis is unknown. There is an over representation of autoimmune disorders in this condition. ${ }^{3-17}$ Furthermore, a luminal factor has been proposed as a possible aetiological agent. ${ }^{18}$ Despite the similarity in symptoms between bile acid malabsorption and collagenous colitis, few attempts have been made to study a possible relation between the two conditions. In a previous study, it was concluded that there is no evidence of bile acid malabsorption in patients with collagenous colitis. ${ }^{19}$ However, according to the ${ }^{75} \mathrm{Se}-$ homocholic acid taurine $\left({ }^{75} \mathrm{SeHCAT}\right)$ test used, one of the eight patients in that study had apparent bile acid malabsorption, and another patient had a borderline value. A few patients have been reported to respond favourably to the bile acid binding agent cholestyramine. ${ }^{320}$ In one extensively investigated patient with collagenous colitis the symptoms and even the histological changes disappeared with cholestyramine treatment. ${ }^{20}$ There was no direct or indirect evidence of bile acid malabsorption in this patient.

In a small retrospective study of 10 patients with collagenous colitis we found the ${ }^{75} \mathrm{SeH}-$ CAT test to be abnormal in five patients, who subsequently responded to treatment with cholestyramine. ${ }^{21}$ These observations have prompted this further study of the role of bile acids in collagenous colitis.

The primary aim of the present study was to investigate prospectively the occurrence of bile acid malabsorption in patients with collagenous colitis. Secondly, we wished to elucidate the potential value of treatment with bile acid binding agents and to see whether the clinical effect was linked to the presence of bile acid malabsorption.

\section{Methods}

Over a period of 36 months all patients $(n=404)$ referred to our Gastroenterology Unit because of severe chronic diarrhoea without blood and with negative faecal culture for bacteria, completed a diagnostic programme which included gastroscopy with duodenal biopsy, colonoscopy with biopsy, and the ${ }^{75} \mathrm{SeHCAT}$ test for bile acid malabsorption. ${ }^{22}$ Some of the patients included had been referred to our hospital because of persistent symptoms and a previous, incomplete diagnostic evaluation. In total 28 patients with collagenous colitis were registered during the three year period. Twenty seven of the patients had persistent severe diarrhoea. In one male patient the symptoms decreased spontaneously after the colonoscopy; this patient declined the ${ }^{75} \mathrm{SeHCAT}$ test and further treatment.

During colonoscopy, biopsy specimens were obtained from the left colon in all patients,
Abbreviation used in this paper: SeHCAT, $\mathrm{Se}$ labelled homocholic acid taurine. 
from the proximal colon in 22 patients, and from the distal ileum in nine patients. Conventional criteria for collagenous colitis were typical microscopic inflammation including an increased number of intraepithelial lymphocytes, and a subepithelial collagen layer of at least $10 \mu \mathrm{m} .{ }^{1{ }^{223}}$ Gastroscopy was performed on all patients and a duodenal biopsy sample was taken for histological evaluation, including a coeliac disease test. In two of three patients with a history of coeliac disease, normalisation of the duodenal mucosa with a gluten free diet had been shown before this study.

${ }^{75}$ SeHCAT TEST

The procedure for measuring ${ }^{75} \mathrm{SeHCAT}$ retention followed the technique described by Thaysen et al. ${ }^{22}$ A capsule containing $0.3 \mathrm{MBq}$ ${ }^{75} \mathrm{SeHCAT}$ was swallowed. Measurements were performed with an uncollimated gamma camera with the patients in a supine position and the gamma camera positioned at a distance of $60 \mathrm{~cm}$. The initial measurement (value for $100 \%$ ) was performed three hours after ingestion of the capsule. Retention was then measured after four and seven days. A retention value of less than $10 \%$ on day 7 was considered abnormal. ${ }^{24}$ Medication that could have a potential effect on bile acid absorption was stopped before the test.

TEST FOR BACTERIAL OVERGROWTH OF THE SMALL BOWEL

The initial 20 patients were tested for bacterial overgrowth, either with the hydrogen breath test after ingestion of $50 \mathrm{~g}$ glucose in $250 \mathrm{ml}$ water (19 patients) or direct culture on duodenal aspirate (one patient). In one patient with a positive breath test, bacterial overgrowth was confirmed by direct culture on a duodenal aspirate. The criteria for positive tests were an increase in the hydrogen concentration of more than $14 \mathrm{ppm}$ over the baseline values ${ }^{26}$ and a culture containing more than $10^{5}$ colonic type bacteria $/ \mathrm{ml}^{27}$ respectively.

STOOL FREQUENCY

The stool frequency was recorded daily and the registration time corresponded to the seven days when the ${ }^{75} \mathrm{SeHCAT}$ test was performed. Data were available for 24 patients.

\section{TREATMENT}

All symptomatic patients $(n=27)$ had a therapeutic challenge with an open label bile acid binder. Twenty four patients were prescribed cholestyramine (Questran, Bristol-Myers Squibb) in dose packets of $4 \mathrm{~g}$. In the case of three patients who reported considerable problems with the smell and the taste of drugs, colestipol (Lestid, Upjohn) was given instead, in dose packets of $5 \mathrm{~g}$. The patients were informed that there is no generally accepted "drug of choice" for collagenous colitis although bile acid binders have been reported to be effective in some patients with this disorder. The patients were instructed to start treatment with one packet two or three times daily. If the effect on diarrhoea was insufficient, they were instructed to increase the dose, if possible up to six packets a day. If constipation occurred, the patients were instructed to decrease the dose. The effect on diarrhoea was evaluated two months after the start of treatment. Rapid improvement was defined as a positive response, with no more than two stools/day, within one week after reaching the optimal dose, and the patients reporting a persistent marked improvement or complete recovery in the diarrhoeal symptoms at the two month control. A few patients had a slow gradual improvement, taking more than two weeks for a clear cut effect but remaining improved at the two month control point. These patients were not classified as rapid responders, although they preferred not to discontinue the bile acid binder treatment.

If bile acid binder treatment failed, we initiated an optional strategy, based partly on previous reports from small studies and partly on the possible risks of long term treatment: instead of the bile acid binder, sulphasalazine (Salazopyrin, Pharmacia) $1 \mathrm{~g}$ twice daily was prescribed for two months. If this therapy failed, metronidazole $0.4 \mathrm{~g}$ was given three times daily for two weeks followed by $0.4 \mathrm{~g}$ twice daily for six months. The final therapeutic option of oral steroids was not necessary as all patients had already responded to one of the previous treatments.

STATISTICAL ANALYSIS

The results for stool frequency are presented as medians, interquartile range, and 10th and 90th percentiles. A comparison between groups with and without bile acid malabsorption was performed using the Mann-Whitney $\mathrm{U}$ test for unpaired data.

\section{Results}

BILE ACID ABSORPTION

Bile acid malabsorption, defined as a ${ }^{75} \mathrm{Se}-$ HCAT retention less than $10 \%$ on day 7 , occurred in 12 of $27(44 \%)$ patients with collagenous colitis. Figure 1 shows the results of the ${ }^{75} \mathrm{SeHCAT}$ test in relation to age and sex. The occurrence of bile acid malabsorption was not significantly related to age or sex.

\section{STOOL FREQUENCY}

Figure 2A shows the mean number of stools per day for individual patients during the week of symptom registration. There was a significant negative correlation between the mean number of stools and the ${ }^{75} \mathrm{SeHCAT}$ retention on day $7(p=0.02)$. Figure $2 B$ shows that stool frequency was significantly higher in patients with collagenous colitis and bile acid malabsorption than in those without bile acid malabsorption.

\section{DURATION OF SYMPTOMS}

Patients with bile acid malabsorption had a significantly longer history of diarrhoea than patients without bile acid malabsorption (median 8 years, range $0.5-30$ years, $n=12$ versus median 2 years, range $0.5-15$ years, $n=15$; $\mathrm{p}<0.05)$. There was no significant relation between the duration of symptoms and the age of the patients. 


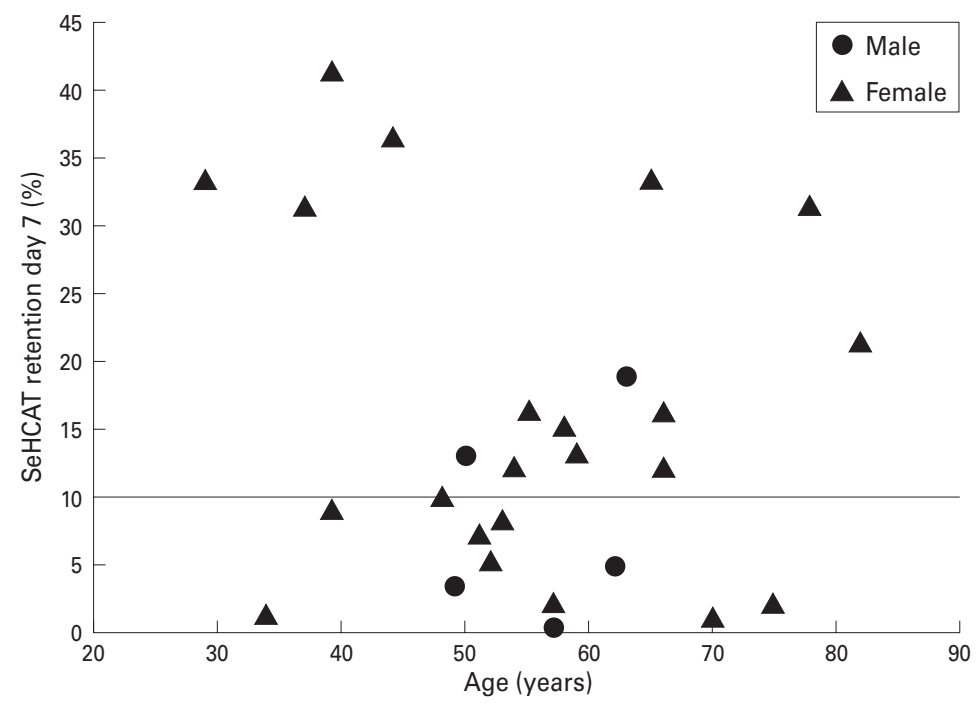

Figure $1{ }^{75}$ SeHCAT retention on day 7 in 27 patients with collagenous colitis.
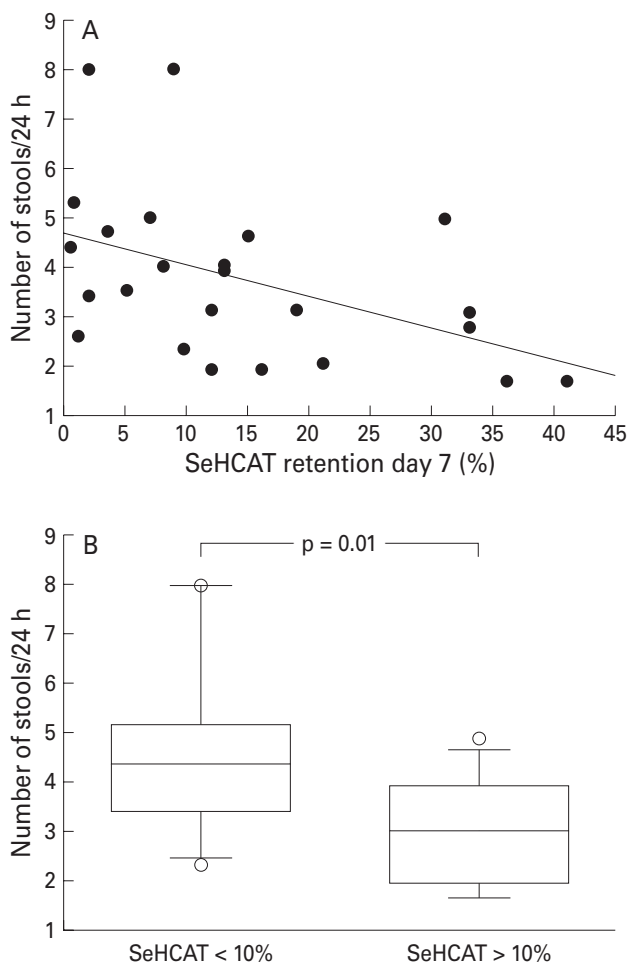

Figure 2 Relation between stool frequency and bile acid malabsorption in patients with collagenous colitis. (A) The mean individual number of stools was negatively correlated to the ${ }^{75} \mathrm{SeHCAT}$ retention on day $7(p=0.02)$. (B) Box plot of stool frequency in patients with and without bile acid malabsorption.

ASSOCIATED DISEASES

Table 1 presents the occurrence of autoimmune diseases and previous abdominal surgery. Eleven patients (41\%) had at least one associated autoimmune disease. Four patients had had one or two abdominal operations, including three patients with cholecystectomy, all showing bile acid malabsorption. Fourteen patients (52\%) had no history of autoimmune disease or a history of abdominal surgery. There was no statistical correlation between autoimmune disease and the occurrence of bile acid malabsorption or between autoimmune disease and sex.

EFFECT OF TREATMENT WITH BILE ACID BINDERS Treatment with a bile acid binder was given to all symptomatic patients (cholestyramine to 24 patients, colestipol to three patients) with collagenous colitis. A rapid improvement with a clear cut decrease in diarrhoea within one week was noted in 21 of the 27 patients ("rapid responders" to bile acid binders). Six patients did not show this rapid response. Eleven of 12 patients with bile acid malabsorption (92\%) showed a rapid response, while in patients with a normal ${ }^{75} \mathrm{SeHCAT}$ test this response rate was $67 \%$. Another two patients, including the nonresponding patient with bile acid malabsorption, improved slowly over a period of one to two months. All the non-responders were women over 50 years old. However, there was no statistically significant relation between sex or age and the outcome of treatment with bile acid binders.

The daily dose of bile acid binder needed to control diarrhoeal symptoms ranged from 0.5 to 6 (median: 2.5) packets daily (cholestyramine $4 \mathrm{~g}$ or colestipol $5 \mathrm{~g}$ per packet). The highest dose needed was cholestyramine $24 \mathrm{~g}$ daily, in one particular patient. This dose could later be reduced to $16 \mathrm{~g}$ daily. All three patients treated with colestipol, one with and two without bile acid malabsorption, responded rapidly to treatment.

OUTCOME OF TREATMENT STRATEGY

Figure 3 illustrates the outcome of treatment of the 27 symptomatic patients with collagenous colitis. Twenty three of the symptomatic patients improved rapidly or slowly when treated with a bile acid binder alone. Three of the remaining four patients, with no improvement or only a slight improvement with a bile acid binder, responded to either sulphasalazine alone (two patients) or an inadvertent combination of cholestyramine and sulphasalazine (one patient). The remaining symptomatic patient responded to metronidazole within two weeks and remained asymptomatic during the long term treatment period of six months with metronidazole $0.8 \mathrm{~g}$ per day.

As all patients with collagenous colitis had sufficient control of the diarrhoea before the fourth optional treatment, steroids were not used in this study.

\section{COLLAGEN LAYER}

Ten of the patients with collagenous colitis had a collagen layer thicker than $20 \mu \mathrm{m}$. The remaining patients had a collagen layer thickness in the range $10-20 \mu \mathrm{m}$. There was no statistical difference in the ${ }^{75} \mathrm{SeHCAT}$ test between the patients with a thick layer (median ${ }^{75} \mathrm{SeHCAT}$ value $11 \%$ ) and those with a layer $10-20 \mu \mathrm{m}$ (median ${ }^{75}$ SeHCAT value $11 \%$ ).

Eight of the nine patients who had ileal biopsies performed had normal histology. Three of these had low ${ }^{75}$ SeHCAT values. One patient with coeliac disease had atrophy of the ileal and the duodenal mucosa but had a normal ${ }^{75}$ SeHCAT value of $13 \%$. All of the 
Table 1 Number of patients with associated conditions, and the individual ${ }^{75}$ SeHCAT values in 27 patients with collagenous colitis

\begin{tabular}{lll}
\hline Disease & $n$ & ${ }^{75}$ SeHCAT retention (\%) \\
\hline Diabetes mellitus & 4 & $9.7 ; 21 ; 33 ; 33$ \\
Coeliac disease & 3 & $5.0 ; 13 ; 31$ \\
Thyroid disease & 2 & $0.8 ; 15$ \\
Rheumatic disease & 2 & $2.0 ; 13$ \\
Dermatitis herpetiformis & 1 & 5.0 \\
Pernicious anaemia & 1 & 33 \\
Abdominal surgery & 1 & 2.0 \\
$\quad$ Cholecystectomy & 1 & 31 \\
Billroth I resection & 1 & 0.8 \\
$\quad$ Cholecystectomy and Billroth I resection & 1 & 5.0
\end{tabular}

Eleven patients (41\%) had at least one autoimmune disease.

Status $\begin{gathered}\text { Registered } \\ \text { patients }\end{gathered}$ Untreated $\begin{gathered}\text { Bile acid } \\ \text { binder }\end{gathered}$
$\begin{aligned} & \text { Rapid } \\ & \text { improvement } \\ & 1-2 \text { weeks }\end{aligned}$
$\begin{aligned} & \text { Slow } \\ & \text { improvement } \\ & >1 \text { month }\end{aligned}$

Figure 3 Resolution of diarrhoea in 28 patients with collagenous colitis.

remaining patients had a normal duodenal histopathology. Consequently, none had collagenous changes of the duodenal or the ileal mucosa.

TEST FOR BACTERIAL OVERGROWTH OF THE SMALL BOWEL

Nineteen patients had a hydrogen breath test and one patient had a culture from duodenal aspirate to test for bacterial overgrowth. Nine of these patients had bile acid malabsorption and 11 patients had normal ${ }^{75}$ SeHCAT values. The bacterial culture on the duodenal aspirate was negative and the breath test showed increased hydrogen values compatible with bacterial overgrowth in only one of the patients tested. In this particular patient, bacterial overgrowth was confirmed by a positive bacterial culture on duodenal aspirate. This patient had a history of cholecystectomy and Billroth I gastric resection due to peptic ulcer disease. As 19 of the first 20 patients tested were negative, and the patient with bacterial overgrowth had a strong predisposing factor, the remaining seven patients were not tested for bacterial overgrowth.

\section{Discussion}

In this prospective study on the potential role of bile acids in collagenous colitis we found using the ${ }^{75} \mathrm{SeHCAT}$ method that bile acid malabsorption occurred in a considerable proportion $(44 \%)$ of the patients. This is in accordance with a few earlier observations in small studies, including our own initial report on the effect of cholestyramine on patients with collagenous colitis. ${ }^{3021}$ As in the previous series of patients with collagenous colitis, our patient group was female dominated and there was a high prevalence of autoimmune diseases, comparable to previous reports. ${ }^{3-17}$ However, the occurrence of bile acid malabsorption in our collagenous colitis patients showed no statistical association with sex, presence of autoimmune disease, or age. The association between bile acid malabsorption and cholecystectomy or gastric resection has been described previously, ${ }^{22}{ }^{28}$ although the present study shows that collagenous colitis might also contribute to diarrhoea in these patients.

The simultaneous occurrence of bile acid malabsorption in patients with collagenous colitis may influence the clinical presentation of the patients. Despite similar histological findings, including the thickness of the collagen layer and similarities in other parameters between patients with and without bile acid malabsorption, patients with bile acid malabsorption had more symptoms, manifested as significantly higher stool frequency.

The patients with collagenous colitis and concomitant bile acid malabsorption had a significantly longer history of diarrhoea than patients without bile acid malabsorption. The reason for this is not obvious from the present data.

The aetiopathogenesis of bile acid malabsorption and collagenous colitis is in many aspects still obscure. The high occurrence of autoimmune disorders in the present and previous reports suggests a genetic predisposition to collagenous colitis. ${ }^{35-17}$ The occurrence of small bowel bacteria or toxins of bacterial origin has also been suggested. ${ }^{14}{ }^{20}$ However, we found no obvious relation between small bowel bacterial overgrowth and collagenous colitis. Only one of 20 patients tested for bacterial overgrowth in this study showed small bowel bacterial overgrowth. This particular patient, apart from a previous cholecystectomy, had also had a previous Billroth I operation predisposing for bacterial overgrowth. ${ }^{29}$ She responded to continuous cholestyramine treatment. This patient had a few later relapses of diarrhoea during cholestyramine treatment. These relapses ceased when treatment for intestinal bacteria with norfloxacin was given for periods of one to two weeks, during which she still had to maintain the ordinary dose of cholestyramine to control the diarrhoea. In this interesting case, the diarrhoea promoting factors bacterial overgrowth and bile acid malabsorption were apparently independent of each other.

Ileal biopsy specimens were available from nine patients, three of whom had bile acid malabsorption. However, ileal histology and duodenal histology were normal except in one patient, who had coeliac disease and atrophy of the ileal and the duodenal mucosa but a normal ${ }^{75} \mathrm{SeHCAT}$ value. As in previous series of patients with microscopic colitis, ${ }^{389}$ there was also an increased proportion of coeliac disease in our study. None of the patients showed signs of collagenous duodenitis or collagenous ileitis, conditions that have been previously described in a few case reports..$^{30-33}$ In the present study, small bowel factors as shown by 
tests of bacterial overgrowth and by the histology of duodenal and ileal mucosa, could not explain the occurrence of collagenous colitis and the associated bile acid malabsorption.

The main pathophysiological mechanism for the occurrence of diarrhoea in collagenous colitis is suggested to be reduced permeability for electrolytes and water in the colonic mucosa, ${ }^{14} 34$ while the active absorption of bile acids occurs in the terminal ileum. ${ }^{35}$ Other diarrhoeal disorders of colonic origin have not been shown to cause abnormal ${ }^{75} \mathrm{SeHCAT}$ values. ${ }^{36}{ }^{37}$ Diarrhoea per se might reduce the ${ }^{75} \mathrm{SeHCAT}$ value but not to an abnormal level. ${ }^{25} 3839$ This suggests that the low ${ }^{75} \mathrm{Se}-$ HCAT values found in the present study correspond to a reduced capacity to absorb bile acids in the ileum and are not due to a colonic malabsorption secondary to the diarrhoea caused by collagenous colitis.

The present prospective study tested whether the clinical response of patients with collagenous colitis to treatment with an open label bile acid binder is related to simultaneous bile acid malabsorption - that is, whether the result of the ${ }^{75} \mathrm{SeHCAT}$ test could predict the outcome of treatment. All patients with bile acid malabsorption, defined as a low value with the ${ }^{75}$ SeHCAT test, responded to bile acid binders. Eleven of 12 patients showed a rapid response. The twelfth patient showed a slower but positive response, which could be a drug effect or it could represent the natural course of the disease similar to the spontaneously improved patient.

There was no statistically significant difference in the response rate in patients with and without bile acid malabsorption. This was due to the relatively high response rate $(67 \%)$ in non-bile acid malabsorption patients. The results suggest that in patients with collagenous colitis and bile acid malabsorption, treatment of the observed bile acid malabsorption was sufficient to obtain a clinical response and none of the drugs used for inflammatory bowel disease was needed. It seems less likely that the rapid response, often within a few days, could correspond to a normalisation of the colonic mucosa. However, no detailed information is as yet available regarding the regression of histological inflammation during bile acid binder treatment although this issue is now under investigation (Ung et al, to be published).

The high response rate to the bile acid binders, even in patients with a normal ${ }^{75} \mathrm{SeHCAT}$ test value, suggests that cholestyramine and colestipol may also have clinical effects on collagenous colitis through mechanisms other than pure bile acid binding. This would be in agreement with a previous case report, where the patient with collagenous colitis responded to cholestyramine. However, direct tests of bile acid malabsorption were not performed in that patient. The mechanisms of cholestyramine were suggested to be binding of toxins and other effects on the intraluminal contents. ${ }^{20}$ Alternatively, the colonic inflammation may be the result of an abnormal reaction to normal amounts of bile acids entering the colon. In this context, it is of interest that in none of our patients could the collagenous colitis related diarrhoea be linked to small bowel bacterial overgrowth.

Hitherto, there has been no generally accepted drug of choice for the treatment of patients with collagenous colitis. In the present study we had a treatment strategy with additional options based on the previously reported effects of sulphasalazine, antibiotics, and steroids. The risk of long term treatment with metronidazole, particularly neuropathy, prompted us to choose sulphasalazine as the second line drug and metronidazole as the third option, should bile acid binders fail. Remarkably, all 27 patients responded to one of the first three choices and steroids, the fourth option, were not prescribed. Further studies are needed to evaluate the histological improvement during the course of the various types of treatment. As steroids do not heal the inflammatory changes in the colonic mucosa in patients with collagenous colitis, ${ }^{40}$ the strategy of using a bile acid binder as the first line treatment with 5-acetylsalicylic acid/sulphasalazine and antibiotics as alternative drugs, seems attractive. Apart from the taste problem and for some patients the smell, as well as the potential need for vitamin supplements, side effects from bile acid binders are rare.

In patients with collagenous colitis without bile acid malabsorption, bile acid binders may also be the first option. However, apart from bile acid binders, bismuth subsalicylate has recently been reported to have a good clinical effect on patients with microscopic colitis. ${ }^{41}{ }^{42}$ In one patient with microscopic colitis, a normal ${ }^{75}$ SeHCAT value, and disabling diarrhoea, refractory to six different drugs including cholestyramine, the response to bismuth subsalicylate was excellent. ${ }^{42}$ Further placebo controlled studies should take various aetiopathogenic factors into consideration and evaluate the effect of bile acid binders, bismuth, and other drugs of potential interest.

In conclusion, the present study shows that a considerable proportion of patients with collagenous colitis have bile acid malabsorption and that in these patients bile acid binders seem to be the first line treatment. Moreover, in collagenous colitis patients without bile acid malabsorption, two thirds responded to a bile acid binder (cholestyramine or colestipol). The results show that bile acids may be an important aetiopathogenic factor, although not the only factor, in patients with collagenous colitis.

This study was supported by the Swedish Medical Research Council (grant 8288) and by the Faculty of Medicine, University of Göteborg. This work was presented in part at the 1997 meeting of the American Gastroenterological Association and published in abstract form (Gastroenterology 1997;112:A1108).

\footnotetext{
1 Lindström CG. "Collagenous colitis" with watery diarrhoea-a new entity? Pathol Eur 1976;11:87-9.

2 Bogomoletz MV, Flejou JF. Newly recognised forms of colitis: collagenous colitis, microscopic (lymphocytic) colitis and lymphoid follicular proctitis. Semin Diagn Pathol

3 Bohr J, Tysk C, Eriksson S, et al. Collagenous colitis: a retrospective study of clinical presentation and treatment in 163 patients. Gut 1996;39:846-51.
} 
4 Merrick MV, Eastwood MA, Ford MJ. Is bile acid malabsorption underdiagnosed? An evaluation of accuracy 1985;290:665-8.

5 Perisic VN, Koka G, Pavlovic M. Coeliac disease and collagenous colitis. Ital fु Gastroenterol 1992;24:418-20.

6 Sylwestrowicz T, Kelly JK, Hwang WS, et al. Collagenous colitis and microscopic colitis: the watery diarrhea-colitis syndrome. Am f Gastroenterol 1989;84:763-8.

7 Arnes J, Gee DC, Macrae FA, et al. Collagenous colitis: jejunal and colorectal pathology. $\mathcal{F}$ Clin Pathol 1992;45:784-7.

8 O'Mahony S, Nawroz IM, Fergusson A. Coeliac disease and collagenous colitis. Postgrad Med F 1990;66:238-41.

9 Breen EG, Farren C, Connoly CE, et al. Collagenous colitis and coeliac disease. Gut 1987;28:364.

10 Esselinckx W, Brenard R, Colin J-F, et al. Juvenile scleroderma and collagenous colitis. The first case. $\mathcal{F}$ Rheumatol 1989;16:834-6.

11 Teglbjaerg PS, Thaysen EH, Jensen HH. Development of collagenous colitis in sequential biopsy specimens. Gastrocollagenous colitis in sequen

12 Wengrower D, Pollak A, Okon E, et al. Collagenous colitis and rheumatoid arthritis with response to sulfasalazine. A case report and review of the literature. $\mathcal{F}$ Clin Gastroentero 1987;9:456-60

13 Roubenoff R, Ratain J, Giardello F, et al. Collagenous colitis, enteropathic arthritis and autoimmune disease: results of a patient survey. F Rheumatol 1989;16:1229-32.

14 Giardiello FM, Bayless TM, Jessurun J, et al. Collagenous colitis: physiologic and histopathologic studies in seven patients. Ann Intern Med 1987;106:46-9.

15 Gubbins GP, Dekovich AA, Ma CK, et al. Collagenous colitis: report of nine cases and review of the literature. South Med F 1991;84:33-7.

16 Sloth H, Bisgaard C, Grove A. Collagenous colitis: a clinicopathological follow-up study. Eur $\mathcal{f}$ Gastroenterol Hepatol 1989;1:73-6.

17 Van Tilburg AJP, Lam HGT, Sedlenrijk CA, et al. Familial occurrence of collagenous colitis. A report of two families. occurrence of collagenous colitis. A

18 Järnerot G, Tysk C, Bohr J, et al. Collagenous colitis and fecal stream diversion. Gastroenterology 1995;109:449-55.

19 Eusufzai S, Löfberg R, Veress B, et al. Studies on bile acid metabolism in collagenous colitis: no evidence of bile acid malabsorption as determined by the SeHCAT test. Eur $\mathcal{F}$ Gastroenterol Hepatol 1992;4:317-21

20 Andersen T, Andersen JR, Trede M, et al. Collagenous colitis: are bacterial cytotoxins responsible? Am f Gastroenterol 1993;88:375-7.

21 Gillberg R, Abrahamsson H. Collagenous colitis and bile salt malabsorption [in Swedish]. Sv Läkarsällskapets Hand Hygiea 1993;102:160.

22 Thaysen EH, Orholm M, Arnfred T, et al. Assessment of ileal function by abdominal counting of the retention of a

gamma emitting bile acid analogue. Gut 1982;23:862-5. phocytic colitis. An evolving concept. Virchows Arch 1994; 424:573-9.

24 Merrick MV. Gall-bladder and colonic retention of SeHCAT: a re-evaluation. Eur $\mathcal{F}$ Nucl Med 1994;21:98890.
25 Fellous K, Jian R, Haniche M, et al. Mesure de lábsorption ileale des sels biliaires par le test à l'homotaurocholate marqué au sélénium 75 . Validation et signification clinique. Gastroenterol Clin Biol 1994;18:865-72.

26 Kerlin P, Wong L. Breath hydrogen testing in bacterial overgrowth of the small intestine. Gastroenterology 1988;95: 982-8.

27 Donaldson RM. Role of enteric microorganism in malabsorption. Fed Proc 1967;26:1426-31.

28 Arlow FL, Dekovich AA, Priest RJ, et al. Bile acid-mediated postcholecystectomy diarrhea. Arch Intern Med 1987;147: 1327-9.

29 Ambrecht U, Boseus I, Gillberg R, et al. Hydrogen $\left(\mathrm{H}_{2}\right)$ breath test and gastric bacteria in achlorhydric and postgastrectomy patients before and after antibiotic treatment. Scand F Gastroenterol 1985;20:805-13.

30 Stolte M, Ritter M, Borchard F, et al. Collagenous gastroduodenitis on collagenous colitis. Endoscopy 1990;22: 186-7.

31 Lewis FW, Warren GH, Goff JS. Collagenous colitis with involvement of terminal ileum. Dig Dis Sci 1991;36:11613.

32 Meier PN, Otto P, Ritter M, et al. Collagenous duodenitis and ileitis in a patient with collagenous colitis [in German]. Leber Magen Darm 1991;21:231-2.

33 Veress B, Löfberg R, Bergman L. Microscopic colitis syndrome. Gut 1995;36:880-6.

34 Gledhill A, Cole FM. Significance of basement membrane thickening in the human colon. Gut 1984;25:1085-8.

35 Lack L. Properties and biological significance of ileal bile salt transport system. Environ Health Perspect 1979;33:7990.

36 Orholm M, Pedersen JO, Arnfred T, et al. Evaluation of the applicability of the SeHCAT test in the investigation of patients with diarrhoea. Scand f Gastroenterol 1988;23:11317.

37 Ferraris R, Galotala G, Barlotta A, et al. Measurement of bile acid half-life using ${ }^{75} \mathrm{SeHAT}$ in health and intestinal diseases. A comparison with ${ }^{75} \mathrm{SeHCAT}$ abdominal retention methods. Dig Dis Sci 1992;37:225-32.

38 Schiller LR, Bilhartz LE, Santa Ana CA, et al. Comparison of endogenous and radiolabeled bile acid excretion in patients with idiopathic chronic diarrhoea. Gastroenterology 1990;98:1036-43.

39 Sciaretta G, Fagiola G, Furno A. ${ }^{75}$ SeHCAT test in the detection of bile acid malabsorption in functional diarrhoea and its correlation with small bowel transit. Gut 1987;28: $970-5$.

40 Sloth H, Bisgaard C, Grove A. Collagenous colitis: a prospective trial of prednisolone in six patients. F Intern Med 1991;229:443-6.

41 Fine KD, Lee EL. Efficacy of open-label bismuth subsalicylate for the treatment of microscopic colitis. Gastroenterology 1998;114:29-36.

42 Abrahamsson $\mathrm{H}$, Ung K-A. "Therapy resistant” microscopic colitis. Effect of bismuth [in Swedish]. Sv Läkarsällskapets Handl Hygiea 1998;107:189. 